\title{
RADIOGRAPHIC STUDY OF MENTAL FORAMEN IN CHITWAN POPULATION
}

\author{
Smriti Narayan Thakur ${ }^{1,}{ }^{*}$, Meena Kumari Mishra ${ }^{1}$, Basuraj Pandey ${ }^{2}$, Harendra Singh ${ }^{3}$, Shrijhana Mishra ${ }^{1}$ \\ ${ }^{1}$ Department of Prosthodontics \& Maxillofacial Prosthetics, Chitwan Medical college, Bharatpur -10, Nepal. \\ ${ }^{2}$ Department of Orthodontics, Chitwan Medical college, Bharatpur -10, Nepal. \\ ${ }^{3}$ Department of Public Health Dentistry, Chitwan Medical college, Bharatpur -10, Nepal.
}

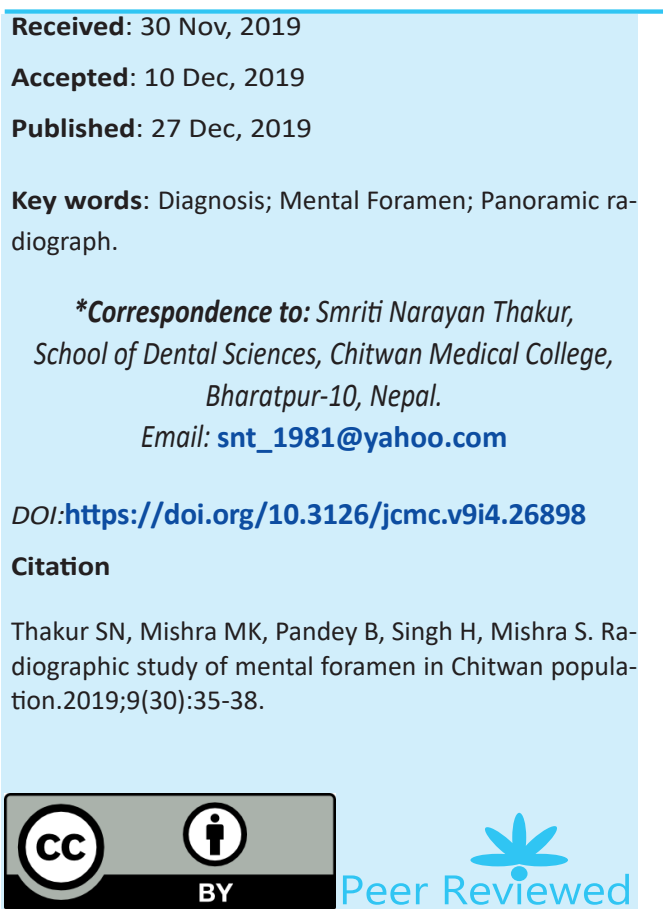

INTRODUCTION

The mental foramen is the terminus of the mental canal \& situated inside the buccal cortical plate of the mandible. The size of the foramen is $4.6 \mathrm{~mm}$ horizontal \& $3.4 \mathrm{~mm}$ vertically on the lateral surface of the mandible. ${ }^{1}$ Mental Nerve emerges from the mental foramen \& innervates the soft tissues of the chin, lower lip \& gingiva on the each side of mandible. ${ }^{2}$

The location of the mental foramen is great importance for several procedures in the field of dentistry like administration of local anaesthesia for surgical, operative or diagnostic purposes, implant placement, extraction procedure \& several other surgical procedures in the mental foramen region of mandible. ${ }^{3}$ Anatomically, mental foramen is present on each side of mandible \& situated in the anterolateral aspect of the body part of the mandible. ${ }^{4}$ The position of mental foramen is very much important for the several clinical procedures such as giving local anaesthesia, fracture management in parasympysisal is of mandible, orthognathic surgery, osteotomies for implant placement, complete denture for mandible. ${ }^{5}$ Radiographically mental foramen appear as a radiolucent area in lower premolar region \& sometimes between the apex of a premolar. ${ }^{6,7}$
The visualization of mental foramen in intraoral radiograph is difficult due to its position below the edge of the film. The proper placement of film inside the patient mouth during radiographic examination is difficult because of several factors such as limited mouth opening, mandibular tori, a shallow floor of mouth \& malalligned teeth. Most of the time mental foramen cannot be captured in periapical radiograph due to its oblique direction in the mesiodistal \& inferiosuperiorplanes. ${ }^{8}$

The accurate identification of the mental foramen is important for proper local anaesthesia \& surgical procedure in the vicinity of mental foramen without any complications. Hence the main purpose of this study was to determine the type, position \& symmetry of mental foramen $\&$ its correlation with age $\&$ sex in Chitwan population using digital panoramic radiographs.

\section{METHODS}

A retrospective study was conducted using 500 OPG (250 Male, 250 Female) of patients with age $15-50$ years who were visited to the Oral medicine \& radiology department, School of Dental Sciences, Chitwan Medical College during the period of Feburary 2017 to Feburary 2019 within age of 15-50 years. The research protocol was approved by the Institution Review 
Committee (IRC) (Ref:CMC-IRC/F/075/076-118) at Chitwan Medical College, Bharatpur, Nepal.

All OPG were taken by Ortholiax OPG (GENDEX, USA). All of the OPG were exposed at tube potential: 66Kv,tube current : $15 \mathrm{~mA}$, time $17.6 \mathrm{~s}$ with the magnification factors $1.2 \& 1.25$ respectively for the posterior border of ramus to canine as reported by the manufacture. The panoramic radiographs were analysed by the same observer to avoid intraobserver variability. All panoramic radiographs were analysed digitally with the help of Dicom Viewer for better localization \& visibility of mental foramen. The type \& position of mental foramen was evaluated on the basis of criteria given by Yosue \& Brooks, Wei Cheong \& Yusof Yuzawati respectively. They were stated as below.

\section{According to Yosue and Brooks ${ }^{9}$}

Type I: Mental canal is continuous with the mandibular canal.

Type II: The foramen is distinctly separated from the mandibular canal.

Type III: Diffuse with a distinct border of the foramen.

Type IV: "Unidentified group."

The position of the image of the mental foramen was recorded as follows ${ }^{10}$

Position 1: Situated anterior to the first premolar.

Position 2: In line with the first premolar.

Position 3: Between the first and second premolar.

Position 4: In line with second premolar.

Position 5: Between the second premolar and first molar.

Position 6: In line with the first molar.

The radiographs were choosen according to the following inclusion \& exclusion criteria Inclusion Criteria. The inclusion criteria are all mandibular teeth between right first molar \& left first molar present, mental foramen was clearly visible on both side \& all permanent set of teeth are fully erupted. The exclusion criteria are patient age below 15 years,missing first molars,any pathology, fracture, supernumerary teeth or impacted teeth\& images with poor resolution or artifact.

\section{RESULTS}

A total 500 Digital Panoramic Radiographs were evaluated for the determination of the type, position \& symmetry of mental foramen among which 250 were males (50\%) \& 250 were females (50\%).All the data were recorded \& studied by performing Chi-Square test.

The most common type of mental foramen was diffuse with a distinct border of the foramen (Type 3) for left side $(n=161,32.2 \%)$ and on the right side ( $n=147,29.4 \%$ as a whole, followed by unidentified group (Type 4) for left side ( $n=145,29 \%$ ) and mental canal continuous with mandibular canal (Type 1) for the right side ( $n=130,26 \%)$ (Tableland 2).In male the most common type of mental foramen was Type 3(n=156,31.2\%) followed by Type2,Type 4 \& Type 1 . In female the most common type of mental foramen was Type $3(n=152,30.4 \%)$ followed by Type 4,Type 1 \&Type 2 (Table 1 and 2).

Table 1: Distribution of Mental Foramen Type in Male

\begin{tabular}{|l|l|l|l|l|}
\hline Type & Right & Left & Total & p-value \\
\hline Type 1 & $60(24 \%)$ & $34(13.6 \%)$ & $94(18.8 \%)$ & \\
\cline { 1 - 4 } Type 2 & $64(25.6 \%)$ & $65(26 \%)$ & $129(25.8 \%)$ & \multirow{2}{*}{0.012019} \\
\hline Type 3 & $76(30.4 \%)$ & $80(32 \%)$ & $156(31.2 \%)$ & \\
\cline { 1 - 4 } Type 4 & $50(20 \%)$ & $71(28.4 \%)$ & $121(24.2 \%)$ & \\
\cline { 1 - 3 } Total & $250(100 \%)$ & $250(100 \%)$ & $500(100 \%)$ & \\
\hline
\end{tabular}

Table 2: Distribution of Mental Foramen Type in Female

\begin{tabular}{|l|l|l|l|l|}
\hline Type & Right & Left & Total & p-value \\
\hline Type 1 & $70(28 \%)$ & $43(17.2 \%)$ & $113(22.6 \%)$ & \\
\cline { 1 - 4 } Type 2 & $55(22 \%)$ & $52(20.8 \%)$ & $107(21.4 \%)$ & \multirow{2}{*}{0.016045} \\
\hline Type 3 & $71(28.4 \%)$ & $81(32.4 \%)$ & $152(30.4 \%)$ & \\
\cline { 1 - 4 } Type 4 & $54(21.6 \%)$ & $74(29.6 \%)$ & $128(25.6 \%)$ & \\
\cline { 1 - 4 } Total & 250(100\%) & 250(100\%) & 500(100\%) & \\
\hline
\end{tabular}

The Type of mental foramen was symmetrical in 225 (90\%) male \& $218(87.20 \%)$ females.. The result was not significant at $\mathrm{p}<0.05$ (Table 3 and Figure 1).

Table 3: Gender wise Distribution of symmetry of Mental Foramen Position

\begin{tabular}{|c|c|c|c|c|}
\hline Sex & Symmetrical & Asymmetrical & Total & p-value \\
\hline Male & $225(90 \%)$ & $25(10 \%)$ & 250 & \multirow{3}{*}{0.3248} \\
\hline Female & $218(87.20 \%)$ & $32(12.80 \%)$ & 250 & \\
\hline Total & 443 & 57 & 500 & \\
\hline $100 \%$ & & & \multirow{6}{*}{\multicolumn{2}{|c|}{$\begin{array}{l}\text { N Symmetrical } \\
\text { m Asymmetrical }\end{array}$}} \\
\hline $80 \%$ & & & & \\
\hline $60 \%$ & & & & \\
\hline $40 \%$ & & & & \\
\hline $20 \%$ & 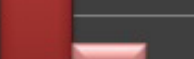 & & & \\
\hline & Male & Female & & \\
\hline
\end{tabular}

Figure 1: Gender wise distribution of symmetry of Type of Mental Foramen

The most frequent location of mental foramen was in the line with second premolar, position 4 for both right side $(n=254,50.8 \%)$ \& left side $(n=221,44.2 \%)$.The second most common location was between first and second premolar,position 3 in left 
side ( $n=154,30.8 \%$ ) \& situated anterior to the first premolar ,Position 1 in right side ( $n=84,16.8 \%$ ) (Table 4 and 5). No case was noted in position 6 in both side of the mandible in total. In male the most common postion of mental foramen was position 4 ( $n=241,48.2 \%)$ followed by position3,1,5and positon 2respectively. But in female the most common position of mental foramen was position $4(n=234,46.8 \%)$ followed by position 3,1, 5\& position 2 sames sequence as male (Table 4 and 5).

Table 4: Distribution of Mental Foramen position in Male

\begin{tabular}{|l|l|l|l|l|}
\hline Position & Right & Left & Totals & p-value \\
\hline P1 & $40(16 \%)$ & $21(8.4 \%)$ & $61(12.2 \%)$ & \\
P2 & $27(10.8 \%)$ & $9(3.6 \%)$ & $36((7.2 \%)$ & \\
\hline P3 & $29(11.6 \%)$ & $82(32.8 \%)$ & $111(22.2 \%)$ & \multirow{2}{*}{$<0.00001$} \\
\hline P4 & $131(52.4 \%)$ & $110(44 \%)$ & $241(48.2 \%)$ & \\
\hline P5 & $23(9.2 \%)$ & $28(11.2 \%)$ & $51(10.2 \%)$ & \\
\cline { 1 - 4 } Total & $250(100 \%)$ & $250(100 \%)$ & $500(100 \%)$ & \\
\hline
\end{tabular}

Table 5: Distribution of Mental Foramen position in Female

\begin{tabular}{|l|l|l|l|l|}
\hline Position & Right & Left & Totals & p-value \\
\hline P1 & $44(17.6 \%)$ & $23(9.2 \%)$ & $67(13.4 \%)$ & \\
\hline P2 & $27(10.8 \%)$ & $11(4.4 \%)$ & $38((7.6 \%)$ & \\
\hline P3 & $35(14 \%)$ & $72(28.8 \%)$ & $107(21.4 \%)$ & \multirow{2}{*}{$<0.00001$} \\
\hline P4 & $123(49.2 \%)$ & $111(44.4 \%)$ & $234(46.8 \%)$ & \\
\hline P5 & $21(8.4 \%)$ & $33(13.2 \%)$ & $54(10.8 \%)$ & \\
\cline { 1 - 4 } Total & $250(100 \%)$ & $250(100 \%)$ & $500(100 \%)$ & \\
\hline
\end{tabular}

The mental foramen location was symmetrical in $206(82.4 \%)$ male and $195(78 \%)$ female.The result was not significant at $p<$ 0.05 (Table 6 and Figure 2).

Table 6: Gender wise Distribution of symmetry of Mental Foramen Position

\begin{tabular}{|l|l|l|l|l|}
\hline Sex & Symmetrical & Asymmetrical & Total & p-value \\
\hline Male & $206(82.4 \%)$ & $44(17.6 \%)$ & 250 & \multirow{2}{*}{0.217} \\
\cline { 1 - 4 } Female & $195(78 \%)$ & $55(22 \%)$ & 250 & \\
\hline Total & 401 & 99 & 500 & \\
\hline
\end{tabular}

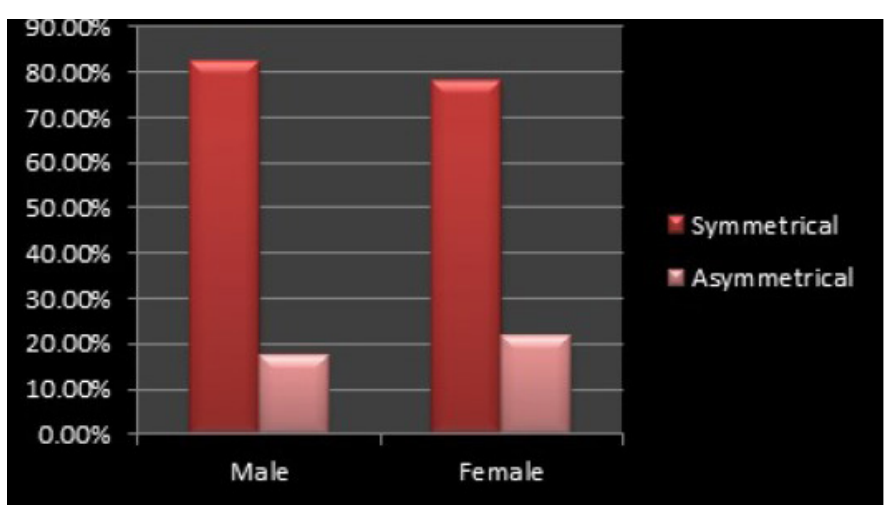

Figure 2: Gender wise distribution of symmetry of Position of Mental Foramen

\section{DISCUSSION}

Radiography is one of the non-invasive methods which are widely used in the field of dentistry for diagnosis \& treatment planning of various types of surgical procedure in mandible. An OPG (Orthopantomogram) is most common imaging tool used for presurgical screening, diagnosis and selecting the best possible surgical approach. ${ }^{11}$

In this study OPG were evaluated from the patients who had completed their growth as studies have showed that the location of mental foramen could change during the development of the jaws bone..$^{12,13}$

Orthopantomogarm has gained popularity in the last three decades over intraoral radiograph to view mental foramen because the entire mandible can be viewed .It gives the more accurate location of the mental foramen in horizontal \& vertical dimensions. ${ }^{8}$ The OPG mode is most commonly used diagnostic means in implant dentistry. ${ }^{14}$

In this study we used Orthopantogram instead of intraoral radiograph because of two reasons first opg reveals whole mandibular continuity in a single image, second it also overcomes the drawbacks of intraoral radiograph as stated by Fisher et al. ${ }^{7,15}$

Youse et al conducted a study on 297 patients \& concluded the most frequent appearance Type 2- The foramen is distinctly separated from the mandibular canal (24\%),followed by Type 3 -Diffuse with a distinct border of the foramen(24\%),Type 1 mental canal continuous with the mandibular canal(21\%),Type 4-unidentified(12\%) where as in this study Type 3 was most common type followed by Type 2,Type 4,\& Type 1respectively in male \& in female also the commonest appearance was Type $3 .{ }^{1}$ Our results showed that the most common postion of mental foramen is postion 4 that is mental foramen in line with second premolar which is similar to the the previous study conducted by Ngeow et al., ${ }^{10}$ Sankar et al., ${ }^{15}$ Ukoha et al., ${ }^{16}$ and Gangotri et al. ${ }^{17}$ But the several previous studies showed the the most common position of mental foramen belongs to the position 3( mental foramen lies between the first \& second premolar) which is similar to our study.

The studies which were perfomed in various ethnic \& racial groups like Chinese, Nigerians\& Asian Indians; their results are similar to our study. ${ }^{16,18,19}$ Our results are also similar to the previous studies which were conducted on dry human skull by Kandel.M et al \& Badhiraja $V$ et al. ${ }^{19,20}$

In conclusion the type \& position on mental foramen varies in different population,but our study showed that the type \& postion of mental foramen is not gender dependent .In majority of population shows bilaterally symmetry type \& Position which is in agreement with previous studies.

The first limitation of the study was the study population, which was included is smaller in size \& conducted in the only Chitwan district of Nepal so it fails short of representing the whole 
sample of different regions of Nepal. The second limitation of the study is the inherent magnification and distortion in Orthopantomogrm could not be controlled.

\section{CONCLUSION}

Determining the variations of type \& position of mental foramen is important for isolation of mental nerves \& vessels when administering local anesthesia \& performing various types of dental surgical procedure. So it is very important to know normal range of possible type \& position of Mental foramen. The most frequent appearance of mental foramen type was type 3 which showed variations from previous studies. But the position of mental foramen results of our study supports the several previous studies which clearly indicates that it has positional variations in different population groups. But the accurate radiographic identification of mental foramen

\section{REFERENCES:}

1. Yosue T, Brooks SL. The appearance of mental foramina on panoramic and periapical radiographs: II. Experimental evaluation. Oral Surgery, Oral Medicine, Oral Pathology. 1989 Oct 1;68(4):488-92. [DOI]

2. Roy PP, Ambali MP, Doshi MA, Jadhav SD. Variation in the position shape and direction of mental foramen in dry mandible. Int J Anat Res. 2014;2(2):418-20.

3. Al-Juboori MJ, Hua CM, Yuen KY. The importance of the mental foramen location detection by using different radiographic technique: Mini review. Int J Med Imaging 2014;2:63-8. [DOI]

4. Gupta S, Soni JS. Study of anatomical variations and incidence of mental foramen and accessory mental foramen in dry human mandibles. Natl J Med Res 2012;2:28-30.

5. Aher V, Pillai P, Ali FM, Mustafa M, Ahire M, Mudhol A, et al. Anatomical position of mental foramen: A review. Glob J Med Public Health 2012;1:61-4.

6. Moiseiwitsch JR. Position of mental foramen in a North American, White population. Oral Surg Oral Med Oral Pathol Oral Radiol Endod 1998;85:457-60. [DOI]

7. Phillips JL, Weller RN, Kulild JC. The mental foramen: 2. Radiographic position in Relation to the mandibular second premolar. J Endod. 1992;18:271-4. [DOI]

8. Phillips JL, Weller RN, Kulild JC. The mental foramen: 3 . Size and position on panoramic radiograph. J Endod. 1992;18:383-6. [DOI]

9. Yosue T, Brooks SL. The appearance of mental foramina on panoramic radiographs. I. Evaluation of patients. Oral Surgery, Oral Medicine, Oral Pathology. 1989 Sep 1;68(3):360-4. [DOI]

10. Ngeow WC, Yuzawati Y. The location of the mental foramen in a selected Malay population. Journal of oral science. 2003;45(3):171-5.

11. Kaffe I, Ardekian L, Gelerenter I, Taicher S. Location of the mandibular foramen in panoramic radiographs. Oral surgery, oral medicine, oral pathology. 1994 Nov 1;78(5):662-9. is paramount to perform any dental surgical procedure in the vicinity of mental foramen.

\section{ACKNOWLEDGEMENTS}

The authors would like to acknoweldge \& thanks all the interns \& staff of School of dental sciences, Chitwan Medical college for their assistance during the research.

\section{CONFLICT OF INTEREST}

\section{None}

\section{FINANCIAL DISCLOSURE}

\section{None}

12. Kjaer I. Formation and early prenatal location of the human mental foramen. Scandinavian journal of dental research. 1989 Feb;97(1):1-7.

13. Radlanski RJ, Renz H, Lajvardi S, Schneider RA. Bone remodeling during prenatal morphogenesis of the human mental foramen. European journal of oral sciences. 2004 Aug;112(4):301-10. [DOI]

14. Güler AU, Sumer M, Sumer P, Biçer I. The evaluation of vertical heights of maxillary and mandibular bones and the location of anatomic landmarks in panoramic radiographs of edentulous patients for implant dentistry. Journal of oral rehabilitation. 2005 Oct;32(10):741-6. [DOI]

15. Sankar DK, Bhanu SP, Susan PJ. Morphometrical and morphological study of mental foramen in dry dentulous mandibles of South Andhra population of India. Indian Journal of Dental Research. 2011 Jul 1;22(4):542-6. [DOI]

16. Ukoha UU, Umeasalugo KE, Ofoego UC, Ejimofor OC, Nzeako HC, Edokwe CG. Position, shape and direction of the mental foramen in mandibles in South-Eastern Nigeria. Int J Biomed Res. 2013 Sep;4(9):499-503

17. Gangotri S, Patni VM, Sathwane RS. Radiographic determination of position and symmetry of mental foramen in Central Indian population. Indian Acad Oral Med Radiol 2011;23:101-3.

18. Green RM. The position of the mental foramen: a comparison between the southern (Hong Kong) Chinese and other ethnic and racial groups. Oral Surgery, Oral Medicine, Oral Pathology. 1987 Mar 1;63(3):287-90. [DOI]

19. Shankland 2 nd WE. The position of the mental foramen in Asian Indians. The Journal of oral implantology. 1994;20(2):118

20. Kadel M, Sedhain BP, Dangol PM. Morphometric analysis of mental foramen in human dry mandibles of nepalese population. Asian Journal of Medical Sciences. 2016 Oct 31;7(6):82-6. [DOI]

21. Budhiraja V, Rastogi R, Lalwani R, Goel P, Bose SC. Study of position, shape, and size of mental foramen utilizing various parameters in dry adult human mandibles from north India. ISRN anatomy. 2012 Dec 17;2013. [DOI] 